\title{
Case Report \\ Localized Subcutaneous Acute Febrile Neutrophilic Dermatosis in a Dog
}

\author{
Karolin Schoellhorn, ${ }^{1}$ Corinne Gurtner, ${ }^{2}$ Petra J. Roosje, ${ }^{3}$ Maja M. Suter, ${ }^{2}$ \\ Bernhard Schoellhorn, ${ }^{1}$ Ulrich Rytz, ${ }^{1}$ and Katrin Timm ${ }^{3}$ \\ ${ }^{1}$ Division of Small Animal Surgery and Orthopedics, Department of Clinical Veterinary Medicine, Vetsuisse Faculty, \\ University of Berne, Laenggassstrasse 128, 3012 Berne, Switzerland \\ ${ }^{2}$ Institute of Animal Pathology, Vetsuisse Faculty, University of Berne, Laenggassstrasse 122, 3012 Berne, Switzerland \\ ${ }^{3}$ Division of Clinical Dermatology, Department of Clinical Veterinary Medicine, Vetsuisse Faculty, University of Berne, \\ Laenggassstrasse 128, 3012 Berne, Switzerland
}

Correspondence should be addressed to Katrin Timm, katrin.timm@vetsuisse.unibe.ch

Received 10 April 2012; Accepted 12 July 2012

Academic Editors: J. Lakritz, C. Noli, and R. M. Santos

Copyright (c) 2012 Karolin Schoellhorn et al. This is an open access article distributed under the Creative Commons Attribution License, which permits unrestricted use, distribution, and reproduction in any medium, provided the original work is properly cited.

A two-year-old spayed female mixed-breed dog was presented with a five-day history of hemorrhagic gastroenteritis and fever. On physical examination, the dog was lethargic and clinically dehydrated. The skin of the entire ventral abdomen extending to both flanks was erythematous, swollen and painful on palpation. Histopathological examination of skin biopsies revealed a severe diffuse neutrophilic dermatitis and panniculitis, resembling the subcutaneous form of Sweet's syndrome in humans. A large part of the skin lesion developed full-thickness necrosis. After intensive care, three surgical wound debridements and wound adaptations, the wound healed by secondary intention within ten weeks. In the absence of infection of the skin or neoplasia, a diagnosis of neutrophilic dermatosis and panniculitis, resembling the subcutaneous form of acute febrile neutrophilic dermatosis, was made.

\section{Introduction}

Canine sterile neutrophilic dermatosis is a very rare disease. The reported clinical and histological features of the disorder in dogs are similar to those described in humans with acute febrile neutrophilic dermatosis (Sweet's syndrome (SS)) [1]. Clinical differential diagnoses in dogs include conditions characterized by erythematous papules, pustules, and plaques, such as erythema multiforme, canine eosinophilic dermatitis, sterile pustular erythroderma of Miniature Schnauzers, superficial pyoderma, pemphigus foliaceus, infectious dermatitides, adverse drug reactions, and toxic shock syndrome $[1,2]$. Extracutaneous clinical signs described in previously reported cases in dogs include fever, arthritis, pneumonia, lameness, and peripheral neutrophilia and lymphadenomegaly [1-4]. As in humans, general malaise and extracutaneous signs often precede the cutaneous manifestations of this syndrome.
Sweet's syndrome in humans is associated with many diseases and divided into three categories depending on its associations: classical or idiopathic SS (often associated with upper respiratory tract or gastrointestinal tract infection, inflammatory bowel disease, or pregnancy), malignancyassociated or paraneoplastic SS (associated with acute leukemia and other neoplastic conditions), and druginduced SS (associated with the administration of granulocyte colony stimulating factor, certain antibiotics, oral contraceptives, diuretics, and other medications) [5]. In addition, a fourth category, known as localized acute febrile neutrophilic dermatosis, has recently been described and is associated with cutaneous trauma [6]. The exact pathogenesis of SS in humans is not known but immune complexes, circulating autoantibodies and cytokines, as well as a hypersensitivity response to a bacterial, tumour or viral antigen are thought to play a role $[5,7-9]$. 
In this paper, we describe new clinical and histological manifestations of canine neutrophilic dermatosis.

\section{Case Presentation}

A two-year-old, $7 \mathrm{~kg}$, spayed female mixed-breed dog was presented to the referring veterinarian for acute febrile $\left(40.3^{\circ} \mathrm{C}\right)$ gastrointestinal hemorrhage and had been treated for three days with different treatment protocols consisting of amoxicillin/clavulanic acid (Clavaseptin, Vetoquinol AG, Ittigen, Switzerland), marbofloxacin (Marbocyl, Vetoquinol AG, Ittigen, Switzerland), metronidazole (Metronidazol B. Braun, B. Braun Medical AG, Sempach, Switzerland), a combination of streptomycin and benzylpenicillin (StreptoPenicillin, Vetoquinol AG, Ittigen, Switzerland), metamizole (Novalgin, Sanofi-Aventis, Meyrin, Switzerland), prednisolone (Prednisolon Streuli, G. Streuli \& Co. AG, Uznach, Switzerland), ranitidine (Zantic, Glaxosmithkline, Muenchenbuchsee, Switzerland), metoclopramide (Paspertin, Abbott, Altishofen, Switzerland), and maropitant (Cerenia, Pfizer, Zuerich, Switzerland). Dosing regimens and frequency of administration were not available. The dog had been vaccinated six months prior to presentation against canine contagious hepatitis, parvovirosis, and distemper and had no previous history of illness.

On the fourth day of treatment, the dog was severely lethargic and was referred for further evaluation. At presentation, the dog was lethargic, dehydrated and had diarrhea which was no longer hemorrhagic. Physical examination revealed an increased heart rate (140 beats per minute), dry and pale mucous membranes, mild generalized peripheral lymphadenomegaly, and a rectal temperature of $39^{\circ} \mathrm{C}$. A large tender erythematous patch with a deep purple- to black-colored center was present covering the entire ventral abdominal area from the caudal thorax to the inguinal region and extending up to both flanks. Ulcerations were seen in the center of the lesion from which a superficial layer could be further peeled off leaving a denuded, exudative surface (Figure 1). Furthermore, some small superficial vesicles were present. Nikolsky's sign was negative over the erythematous skin; the outer layer of skin was not rubbed off by applying pressure to it indicating no sign of poor cellular cohesion. In the darker colored part of the lesion; the skin did not blanche on diascopy. Differential diagnoses were a chemical or thermal burn, vasculitis, possibly associated with septicemia, cutaneous adverse drug reaction, and toxic epidermal necrolysis.

A complete blood count and serum chemistry profile revealed leukocytosis $\left(24.8 \times 10^{9} / \mathrm{L}\right.$; reference range $6-$ $12 \times 10^{9} / \mathrm{L}$ ) with a left shift (band neutrophils $12.78 \times$ $10^{9} / \mathrm{L}$; reference range $0-0.3 \times 10^{9} / \mathrm{L}$ ) and hypoalbuminemia ( $12 \mathrm{~g} / \mathrm{L}$; reference range $29.7-40 \mathrm{~g} / \mathrm{L}$ ). The coagulation profile was within normal limits. Survey laterolateral and ventrodorsal thoracic radiographs and abdominal ultrasound were unremarkable.

Cytological examination of impression smears taken from an opened superficial vesicle showed numerous rodshaped bacteria and neutrophils. Culture from this lesion

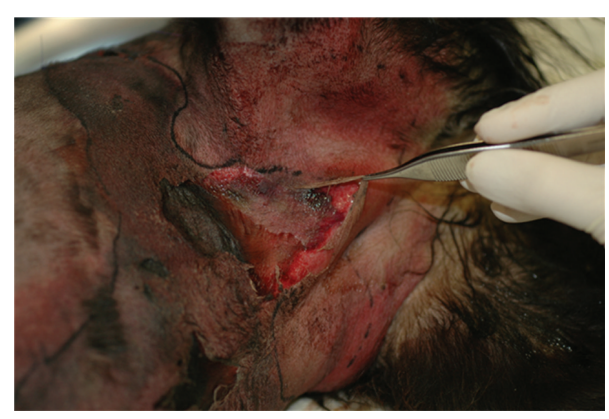

FIGURE 1: Photograph of skin lesions at the time of presentation: a large erythematous patch with a dark ulcerative center is visible extending across the entire ventral abdominal area up to both flanks. A superficial layer can be peeled off leaving a denuded surface.

subsequently revealed growth of Pseudomonas aeruginosa. Antibiotic sensitivity testing indicated the bacteria to be resistant to chloramphenicol, tetracycline, and trimethoprim sulfonamide but sensitive to ciprofloxacin and enrofloxacin as well as to ceftazidim.

Multiple skin punch biopsies were taken for histopathological examination which demonstrated a severe interstitial, neutrophilic deep dermatitis, and neutrophilic panniculitis. Analogous to the progression of the macroscopic skin lesions, histopathological findings varied in severity between those taken from areas with mild erythema to those taken in areas with necrosis. The dominating feature was an increasing perivascular-to-interstitial infiltration of neutrophils with a more intense infiltration of the subcutis than the dermis. In the mildly erythematous samples, the moderate infiltrate of mainly mature neutrophils was located in the septa of the subcutis and extended between the muscle fibers (Figure 2(a)), while the same cells were just sprinkled as single cells throughout the dermis. The blood vessels seemed to be free of changes. In more marked macroscopic lesions characterized by a dark-red skin color, a progression to a more severe perivascular-to-diffuse infiltration of the subcutis and the dermis with degenerate neutrophils, some round cells, and scattered karyorrhectic debris was seen (Figure 2(b)). Marked edema was present in the subepidermal dermis and in a lesser degree in the deep dermis. In some blood vessels there was leukocytostasis with neutrophils often attached to the vascular endothelium. The sample presenting a grossly visible vesicle showed severe diffuse interstitial infiltration of mainly degenerate neutrophils in the dermis and subcutis, in-between the muscle fibers, and in the fascia, and multifocal to coalescing necrosis with disseminated karyorrhectic debris and subcutaneous thrombosis of involved vessels (Figure 2(c)). The necrotic epidermis was either separated from the dermis leaving the dermis denuded or severely degenerate with hydropic and beginning ballooning changes with hypereosinophilic cytoplasm and multifocal nuclear pyknosis (Figure 2(d)). Sub- and intraepidermally, there was a severe infiltration with mainly degenerate neutrophils forming a pustule. In the sample with epidermal necrosis, the necrotic changes 


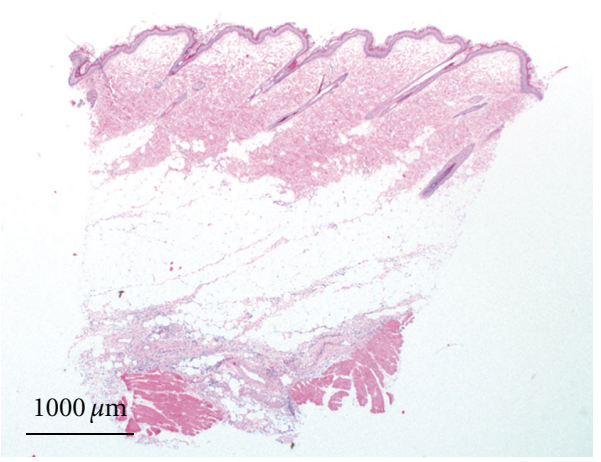

(a)

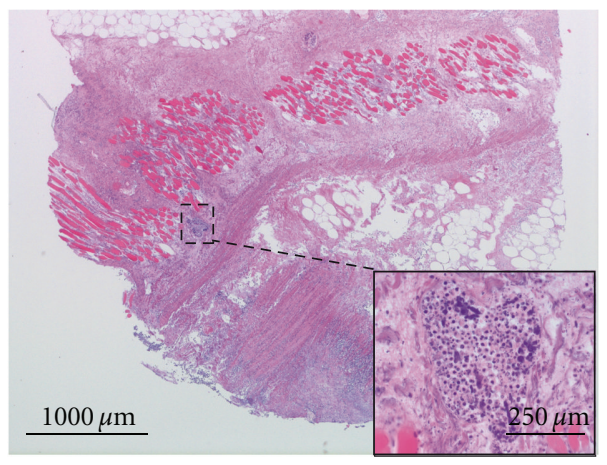

(c)



(b)

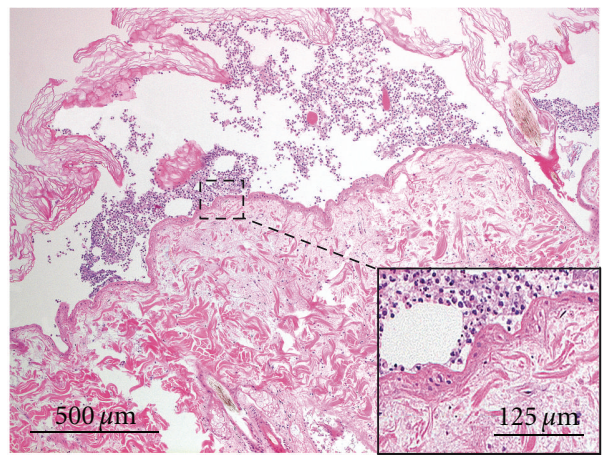

(d)

FIGURE 2: Histopathological images stained with hematoxylin and eosin (H\&E) illustrating the histologic progression of severity analogous to the progression of macroscopic lesions. (a) Haired skin, the overview demonstrates a moderate infiltrate of neutrophils in the septa of the subcutis and extending between muscle fibers. Original magnification $\times 20$. (b) Haired skin, epidermis and dermis: there is a perivascular to interstitial infiltrate of neutrophils (inset) in the dermis, giving the appearance of being sprinkled throughout the tissue. Original magnification $\times 100$, inset $\times 400$. (c) Haired skin, subcutis and muscle fibers: diffuse necrosis with disseminated karyorrhectic debris and subcutaneous thrombosis of involved vessels (inset). Original magnification $\times 40$, inset $\times 400$. (d) Haired skin, epidermis and dermis: the epidermis (inset) is hypereosinophilic and necrotic with severe infiltration with mainly degenerate neutrophils forming an intraepidermal pustule. The dashed line marks the border between dermis and necrotic epidermis. Original magnification $\times 100$, inset $\times 400$.

reached below the subcutis, affecting also the adnexa. The epidermis showed the same features as in the aforementioned sample but without the sub- and intraepidermal infiltrate. The dermis and subcutis were severely edematous, the collagen fibers were swollen and hyalinized, and there was widespread hemorrhage, all providing evidence for vascular damage. The inflammatory infiltration in the dermis was as described in the former samples.

The dog was treated with intravenous fluids, gastric protection therapy, analgesics, and antibiotics and dexamethasone (Table 1). On the third day, diarrhea had resolved, but the dog continued to vomit intermittently for three more weeks. By the seventh day, the dog's general condition had improved, the erythema at the margins of the patch resolved, and a large part of the darker colored center of the erythematous patch was demarcated (Figure 3 ). The necrotic skin was debrided, and partial closure of the defect was performed under general anesthesia. After 17 days of hospitalization, the leukocytes were within normal range, and the neutrophil left shift was absent after 33 days. Hypoalbuminemia normalized within 26 days.
Four weeks after initial presentation, an autologous fullthickness mesh graft was placed over a healthy bed of granulation tissue. A vacuum-assisted closure device was applied with continuous suction for five days, and the wound dressing was changed every three days [10]. The graft failed and was removed six days after surgery but multiple skin punch grafts, performed two weeks later, were successful. The remaining wound healed by secondary intention (Figure 4). Further wound treatment included daily wound irrigation with a full electrolyte solution (Plasma-Lyte A, Baxter AG, Volketswil, Switzerland) and a nonadhering wound dressing (Adaptic, Sytagenix Wound Management Limited, Gargrave, North Yorkshire, UK) until healing was complete.

The dog remained hospitalized for a total of ten weeks to ensure proper wound care. During this time the dog remained normothermic and was finally discharged from the hospital in good general condition and with a nearly resolved skin lesion. Complete healing of the lesion occurred after 12 weeks (Figure 5). On follow-up telephone consultation with the owner eight months after discharge, the dog was in excellent general condition and did not receive any further treatment. 
TABLE 1: Protocol of the administered drugs during hospitalization of the dog. All listed drugs were administered from the day of presentation onwards, unless mentioned otherwise.

\begin{tabular}{|c|c|c|}
\hline Drug ingredient & Dose and form of application & Duration of application \\
\hline \multicolumn{3}{|l|}{ Antibiotics } \\
\hline Enrofloxacin ${ }^{\mathrm{a}}$ & $11 \mathrm{mg} / \mathrm{kg}$ per os $(\mathrm{PO}) q 12 \mathrm{hr}$ & 6 weeks \\
\hline Amoxicillin/clavulanic acid ${ }^{\mathrm{b}}$ & $20 \mathrm{mg} / \mathrm{kg}$ intravenously (IV) $q 8 \mathrm{hr}$ & 5 weeks \\
\hline Amoxicillin/clavulanic acid ${ }^{c}$ & $12.5 \mathrm{mg} / \mathrm{kg} \mathrm{PO} q 12 \mathrm{hr}$ & 2 weeks (following IV administration) \\
\hline Metronidazole $^{\mathrm{d}}$ & $15 \mathrm{mg} / \mathrm{kg}$ IV q $12 \mathrm{hr}$ & 1 week \\
\hline \multicolumn{3}{|l|}{ Glucocorticoids } \\
\hline Dexamethasone $e^{e}$ & $0.15 \mathrm{mg} / \mathrm{kg}$ IV $q 12 \mathrm{hr}$ & 6 days \\
\hline Prednisolone $\mathrm{f}^{\mathrm{f}}$ & $2 \mathrm{mg} / \mathrm{kg} \mathrm{PO} q 24 \mathrm{hr}$ & $\begin{array}{l}2 \text { weeks (following dexamethasone), then gradually } \\
\text { tapered over } 4 \text { weeks }\end{array}$ \\
\hline \multicolumn{3}{|l|}{ Analgesics } \\
\hline Fentanylg & $\begin{array}{c}2.5-7.5 \mu \mathrm{g} / \mathrm{kg} / \mathrm{hr} \text { constant rate infusion } \\
\text { (CRI) }\end{array}$ & 10 days \\
\hline Ketamine $^{\mathrm{h}}$ & $10 \mu \mathrm{g} / \mathrm{kg} / \mathrm{hr}$ CRI & 8 days \\
\hline Buprenorphine $^{\mathrm{i}}$ & $0.01-0.02 \mathrm{mg} / \mathrm{kg}$ subcutaneously $q 8 \mathrm{hr}$ & 3 weeks \\
\hline Tramadol ${ }^{j}$ & $3 \mathrm{mg} / \mathrm{kg} \mathrm{PO} q 8 \mathrm{hr}$ & 3 weeks \\
\hline \multicolumn{3}{|l|}{ Gastric protection } \\
\hline Omeprazole $\mathrm{k}^{\mathrm{k}}$ & $1 \mathrm{mg} / \mathrm{kg} \mathrm{PO} q 24 \mathrm{hr}$ & 7 weeks \\
\hline Sucralfate $e^{1}$ & $30 \mathrm{mg} / \mathrm{kg} \mathrm{PO} q 12 \mathrm{hr}$ & 10 days \\
\hline Metoclopramide ${ }^{\mathrm{m}}$ & $0.2 \mathrm{mg} / \mathrm{kg}$ IV $q 6 \mathrm{hr}$ & 10 days \\
\hline Dolasetrone $\mathrm{e}^{\mathrm{n}}$ & $0.5 \mathrm{mg} / \mathrm{kg} q 24 \mathrm{hr}$ & 7 days \\
\hline \multicolumn{3}{|l|}{ Fluid therapy } \\
\hline Full electrolyte solution ${ }^{\circ}$ & $1-4 \mathrm{~mL} / \mathrm{kg} / \mathrm{hr} \mathrm{CRI}$ & 4 weeks \\
\hline
\end{tabular}

${ }^{\mathrm{a} B a y t r i l}$ 2.5\%, Provet AG, Lyssach, Switzerland; ${ }^{\mathrm{b}}$ Augmentin Adult, Glaxosmithkline, Muenchenbuchsee, Switzerland; ${ }^{\mathrm{c}}$ Clavaseptin, Vetoquinol AG, Ittigen, Switzerland; ' ${ }^{\mathrm{d}}$ Metronidazol B. Braun, B. Braun Medical AG, Sempach, Switzerland; ${ }^{\mathrm{D}}$ Dexatat, Dr. E. Graeub AG, Bern, Switzerland; ${ }^{\mathrm{f}}$ Prednisolon Streuli, G. Streuli \& Co. AG, Uznach, Switzerland; ${ }^{\mathrm{g}}$ Sintenyl i.v. $0.5 \mathrm{mg}$, Sintetica S.A., Mandrisio, Switzerland; ${ }^{\mathrm{h}}$ Ketasol, Dr. E. Graeub AG, Bern, Switzerland; ${ }^{\mathrm{i} T e m g e s i c}$, Essex Pharma GmbH, Munich, Germany; 'Tramadol-Mepha 50 retard, Mepha Pharma AG, Aesch, Switzerland; kOmeprazol-Teva, Teva Pharma AG, Aesch, Switzerland; ${ }^{1}$ Ulcogant Suspension, Merck Serono GmbH, Darmstadt, Germany; ${ }^{m}$ Paspertin, Abbott, Altishofen, Switzerland; ${ }^{\mathrm{n} A n z e m e t, ~ S a n o f i-A v e n t i s ; ~}$ Meyrin, Switzerland; ${ }^{\circ}$ Plasma-Lyte A, Baxter AG, Volketswil, Switzerland.

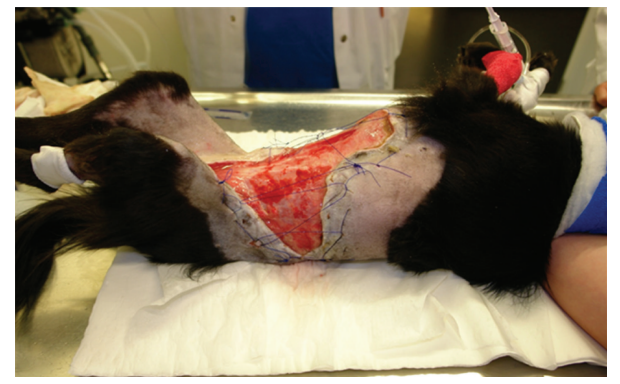

FIGURE 3: Photograph of skin lesions on day 7 after surgical debridement of necrotic areas: necrotic skin has been surgically resected after demarcation. Complete wound closure is not possible. The suture reduces the tension of the wound and holds the wound dressing in position.

\section{Discussion}

The cardinal features of SS in humans are an acute onset of general malaise, fever, marked leukocytosis, and the development of tender erythematous skin lesions with histological

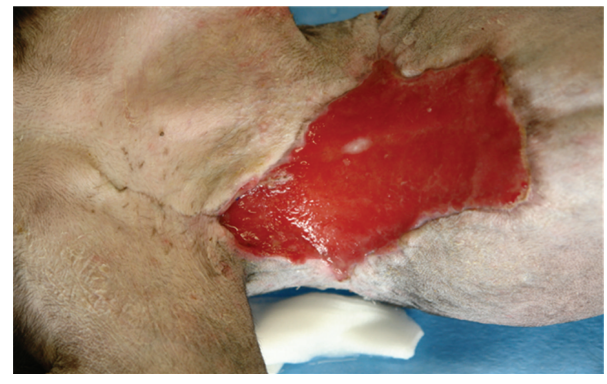

Figure 4: Photograph of skin lesions on day 38: granulation tissue is visible covering the wound.

evidence of perivascular-to-interstitial dermal infiltrate of mature neutrophils $[5,8,11]$. In humans and in the five previously reported cases in dogs, multiple lesions including erythematous plaques, nodular, pustular, and papular lesions are described, unlike the single large lesion in the case reported herein $[2-5,8,9,11,12]$. It is also noteworthy that this dog survived whereas three of five previously described dogs died of the disease $[2,3]$. Both surviving dogs were 


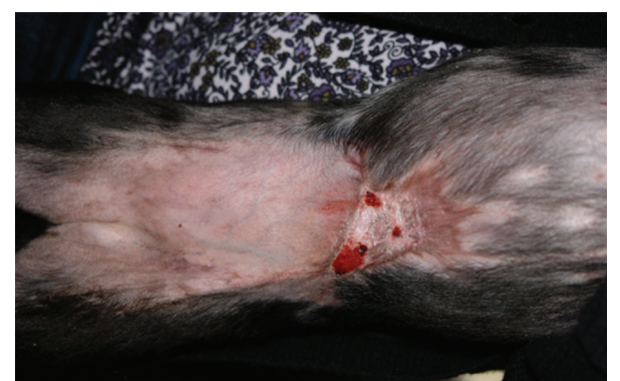

Figure 5: Photograph of skin lesions on day 84: almost complete wound healing is visible.

treated with corticosteroids soon after admission, as was the dog in this paper. In humans with classical SS, an excellent response to systemic corticosteroids is one of the criteria used to confirm diagnosis [5]. This positive effect of corticosteroids would seem to uphold the theory that SS is a sterile inflammatory process caused by an exaggerated immune response in otherwise immunocompetent patients.

The dog in this paper was initially presented to the referring veterinarian with signs of hemorrhagic gastroenteritis, which is consistent with the association with gastrointestinal disorders observed in some human classical SS cases $[8,11$, 13-17]. However, it is unclear as to whether the inciting cause was a gastrointestinal disorder or the administration of drugs in this case. Drug-induced SS in people is associated with a large variety of drugs in humans, including nonsteroidal anti-inflammatory drugs and antibiotics [14, 1622]. Moreover, carprofen was administered to three of the five previously reported dogs affected with SS, and firocoxib was administered to the fourth [2-4]. Although these drugs were not administered to the dog in the present paper, the COX inhibitor metamizole was, as well as a number of different antibiotics. Therefore a drug-induced etiology cannot be excluded. In contrast, a possible paraneoplastic etiology of SS was ruled out based on our diagnostic workup and a follow-up time of several months. A previous local trauma could be excluded as there was no evidence for it in the history.

The common histological feature of SS is a uniform, dense, moderate-to-extensive infiltrate of neutrophils in the upper dermis. The epidermis is usually normal, although mild reactive changes may be seen $[5,8,23]$. Variable dermal edema is not uncommon, sometimes leading to subepidermal bulla formation which suggests the appearance of a vesicle. Based on the histopathological findings in the skin biopsies, a subcutaneous form of neutrophilic dermatosis is possible in the dog in this paper. A lobular or septal panniculitis or both are described features of subcutaneous SS in humans $[5,11,24,25]$. In this variant of SS, the neutrophilic infiltrate may remain localized to the subcutaneous fat or extend secondarily to the overlying dermis, as seen in the present case $[5,24]$. A neutrophilic septal panniculitis was also described in one previously reported dog with SS-like disease [2].

Vasculitis, which was observed in the dog in this paper, was initially a criterion for exclusion of a diagnosis of SS in humans. However, it is now recognized that leukocytoclastic vasculitis does occur in many SS patients, although it is unclear as to whether this represents a primary or secondary epiphenomenon in SS $[5,25,26]$. Vasculitis was also described in three of the five previously reported canine cases $[3,4]$. Depending on the size, the number of involved vessels, and intensity of released cytokines, it is possible that necrosis developed as a result of vasculitis in the subcutis in the reported case, especially as necrosis was not observed in the areas in which vasculitis was not seen.

Some of the clinical and histological signs in the dog described herein are similar to those described in a dog with sterile neutrophilic nodular panniculitis in which a vasculitis was identified as well as those described in a dog with SSlike skin and extracutaneous lesions in which a neutrophilic septal panniculitis and vasculitis at extracutaeous sites were diagnosed histologically $[2,27]$. Both conditions may represent part of a spectrum of signs of the same syndrome elicited by an immune response to an infection or other stimulus. The common features of the syndrome appear to include an acute onset, fever, a prodromal inflammatory process or drug history, and a range of lesions including vasculitis and panniculitis. The term canine acute febrile neutrophilic dermatosis may therefore be more appropriate than the currently used name canine sterile neutrophilic dermatosis, until more is understood about the pathophysiology of this condition in the dog. Furthermore, the role of bacteria as a primary or secondary agent is not evident in this particular case, as depicted below. Therefore the term "sterile" was avoided in the description of the diagnosis.

Although a favorable response to corticosteroids is reported in canine sterile nodular panniculitis, thus far only three reported dogs with SS-like disease survived, including our case. It is therefore unclear if treatment response may be used as a diagnostic criterion in dogs as in the human counterpart.

In the reported case differential diagnoses for the presenting clinical sign of an erythematous patch included a severe chemical or thermal burn but these were ruled out based on history and histopathology, in particular because a dense neutrophilic infiltrate in the subcutis with only few neutrophils in the dermis was found in less severely affected areas of the skin, suggesting an insult initiated in the deeper areas of the skin.

Culture of Pseudomonas aeruginosa from the surface swabs of the necrotic skin may suggest primary pyoderma or septicemia-induced cutaneous necrosis. However, bacteria were not observed on routine histopathology. Additionally, histopathological changes were not consistent with those expected in primary pseudomonal dermatitis, such as primary suppurative folliculitis and furunculosis with pyogranulomatous dermatitis and panniculitis, or sepsis characterized histologically by dermal necrosis associated with severe vascular fibrinoid necrosis and fibrin thrombi $[28,29]$. Septicemia was also considered unlikely based on the results of hematology and coagulation profile. Blood cultures were not performed. With the information available, Pseudomonas aeruginosa was judged to be a secondary bacterial contaminant, probably restricted to the necrotic 
area without further impact on the etiology or pathogenesis of the disease.

In summary, this paper describes a dog with unusual clinical and histological signs of SS-like disease or acute febrile neutrophilic dermatosis with a favorable response to treatment.

\section{Acknowledgments}

The authors would like to thank Judith Howard and Thierry Francey for the critical reading of the paper.

\section{References}

[1] T. L. Gross, P. J. Ihrke, E. J. Walder et al., "Canine sterile neutrophilic dermatosis (Sweet's syndrome)," in Skin Diseases of the Dog and Cat, pp. 366-368, Blackwell Science, 2005.

[2] C. S. Johnson, E. R. May, R. K. Myers, and J. M. Hostetter, "Extracutaneous neutrophilic inflammation in a dog with lesions resembling Sweet's syndrome," Veterinary Dermatology, vol. 20, no. 3, pp. 200-205, 2009.

[3] C. B. Vitale, E. Zenger, and J. Hill, "Putative Rimadyl-induced neutrophilic dermatosis resembling Sweet's syndrome in two dogs," in Proceedings of the 15th Annual Meeting of the American Academy of Veterinary Dermatology and American College of Veterinary Dermatology, pp. 69-70, 1999.

[4] P. J. Mellor, A. J. A. Roulois, M. J. Day, B. A. Blacklaws, S. J. Knivett, and M. E. Herrtage, "Neutrophilic dermatitis and immune-mediated haematological disorders in a dog: suspected adverse reaction to carprofen," Journal of Small Animal Practice, vol. 46, no. 5, pp. 237-242, 2005.

[5] P. R. Cohen, "Sweet's syndrome-a comprehensive review of an acute febrile neutrophilic dermatosis," Orphanet Journal of Rare Diseases, vol. 2, no. 1, article 34, 2007.

[6] Y. S. Phua, S. A. Al-Ani, R. B. W. She, and T. M. de Chalain, "Sweet's syndrome triggered by scalding: a case study and review of the literature," Burns, vol. 36, no. 4, pp. e49-e52, 2010.

[7] N. P. Burrows, "Anti-neutrophil cytoplasmic antibodies in Sweet's syndrome," Journal of the American Academy of Dermatology, vol. 31, no. 5 I, pp. 825-826, 1994.

[8] P. R. Cohen and R. Kurzrock, "Sweet's syndrome: a neutrophilic dermatosis classically associated with acute onset and fever," Clinics in Dermatology, vol. 18, no. 3, pp. 265-282, 2000.

[9] P. R. Cohen, H. Hönigsmann, and R. Kurzrock, "Acute febrile neutrophilic dermatosis (Sweet syndrome)," in Fitzpatrick's Dermatology in General Medicine, K. Wolff, L. A. Goldsmith, S. I. Katz et al., Eds., pp. 289-295, McGraw-Hill Professional, New York, NY, USA, 2007.

[10] R. Ben-Amotz, O. I. Lanz, J. M. Miller, D. E. Filipowicz, and M. D. King, "The use of vacuum-assisted closure therapy for the treatment of distal extremity wounds in 15 dogs," Veterinary Surgery, vol. 36, no. 7, pp. 684-690, 2007.

[11] P. R. Cohen and R. Kurzrock, "Sweet's syndrome revisited: a review of disease concepts," International Journal of Dermatology, vol. 42, no. 10, pp. 761-778, 2003.

[12] M. J. Gains, A. Morency, F. Sauvé, M. C. Biais, and Y. Bongrand, "Canine sterile neutrophilic dermatitis (resembling Sweet's syndrome) in a Dachshund," Canadian Veterinary Journal, vol. 51, no. 12, pp. 1397-1399, 2010.
[13] O. Fain, E. Mathieu, N. Feton et al., "Intestinal involvement in Sweet's syndrome," Journal of the American Academy of Dermatology, vol. 35, no. 6, pp. 989-990, 1996.

[14] D. C. Walker and P. R. Cohen, "Trimethoprim-sulfamethoxazole-associated acute febrile neutrophilic dermatosis: case report and review of drug-induced Sweet's syndrome," Journal of the American Academy of Dermatology, vol. 34, no. 5, pp. 918-923, 1996.

[15] A. Vaz, K. Kramer, and R. A. Kalish, "Sweet's syndrome in association with Crohn's disease," Postgraduate Medical Journal, vol. 76, no. 901, pp. 713-714, 2000.

[16] K. H. Fye, E. Crowley, T. G. Berger, P. E. LeBoit, and M. K. Connolly, "Celecoxib-induced Sweet's syndrome," Journal of the American Academy of Dermatology, vol. 45, no. 2, pp. 300302, 2001.

[17] B. K. Durani and U. Jappe, "Drug-induced Sweet's syndrome in acne caused by different tetracyclines: case report and review of the literature," British Journal of Dermatology, vol. 147, no. 3, pp. 558-562, 2002.

[18] C. Kaur, R. Sarkar, and A. J. Kanwar, "Fixed drug eruption to rofecoxib with cross-reactivity to sulfonamides," Dermatology, vol. 203, no. 4, article 351, 2001.

[19] J. Levang, P. Muller, P. Girardin, and P. Humbert, "Sweet's syndrome and phenylbutazone-induced sialadenitis," Annales de Dermatologie et de Venereologie, vol. 135, no. 4, pp. 291-294, 2008.

[20] C. R. Retief and F. D. Malkinson, "Nitrofurantoin-associated Sweet's syndrome," Cutis, vol. 63, no. 1-3, pp. 177-179, 2001.

[21] D. Aguiar-Bujanda, J. Aguiar-Morales, and U. Bohn-Sarmiento, "Sweet's syndrome associated with norfloxacin in a prostate cancer patient," QJM: An International Journal of Medicine, vol. 97, no. 1, pp. 55-56, 2004.

[22] D. Özdemir, U. Korkmaz, I. Şahin et al., "Ofloxacin induced Sweet's syndrome in a patient with Crohn's disease," Journal of Infection, vol. 52, no. 5, pp. e155-e157, 2006.

[23] R. L. Fitzgerald, "Review: Sweet's syndrome," International Journal of Dermatology, vol. 35, no. 1, pp. 9-15, 1996.

[24] P. R. Cohen, "Subcutaneous Sweet's syndrome: a variant of acute febrile neutrophilic dermatosis that is included in the histopathologic differential diagnosis of neutrophilic panniculitis," Journal of the American Academy of Dermatology, vol. 52, no. 5, pp. 927-928, 2005.

[25] G. Ratzinger, W. Burgdorf, B. G. Zelger, and B. Zelger, "Acute febrile neutrophilic dermatosis: a histopathologic study of 31 cases with review of literature," American Journal of Dermatopathology, vol. 29, no. 2, pp. 125-133, 2007.

[26] J. C. Malone, S. P. Slone, L. A. Wills-Frank et al., "Vascular inflammation (vasculitis) in Sweet syndrome: a clinicopathologic study of 28 biopsy specimens from 21 patients," Archives of Dermatology, vol. 138, no. 3, pp. 345-349, 2002.

[27] J. R. S. Dandrieux, K. Timm, P. J. Roosje et al., "Unusual systemic signs in a dog with sterile neutrophilic-macrophagic lymphadenitis and nodular panniculitis," Journal of the American Animal Hospital Association, vol. 47, no. 2, pp. 117-121, 2011.

[28] A. Hillier, J. R. Alcorn, L. K. Cole, and J. J. Kowalski, "Pyoderma caused by Pseudomonas aeruginosa infection in dogs: 20 cases," Veterinary Dermatology, vol. 17, no. 6, pp. 432-439, 2006.

[29] T. L. Gross, P. J. Ihrke, E. J. Walder et al., "Septic vasculitis," in Skin Diseases of the Dog and Cat, pp. 238-239, Blackwell Science, 2005. 

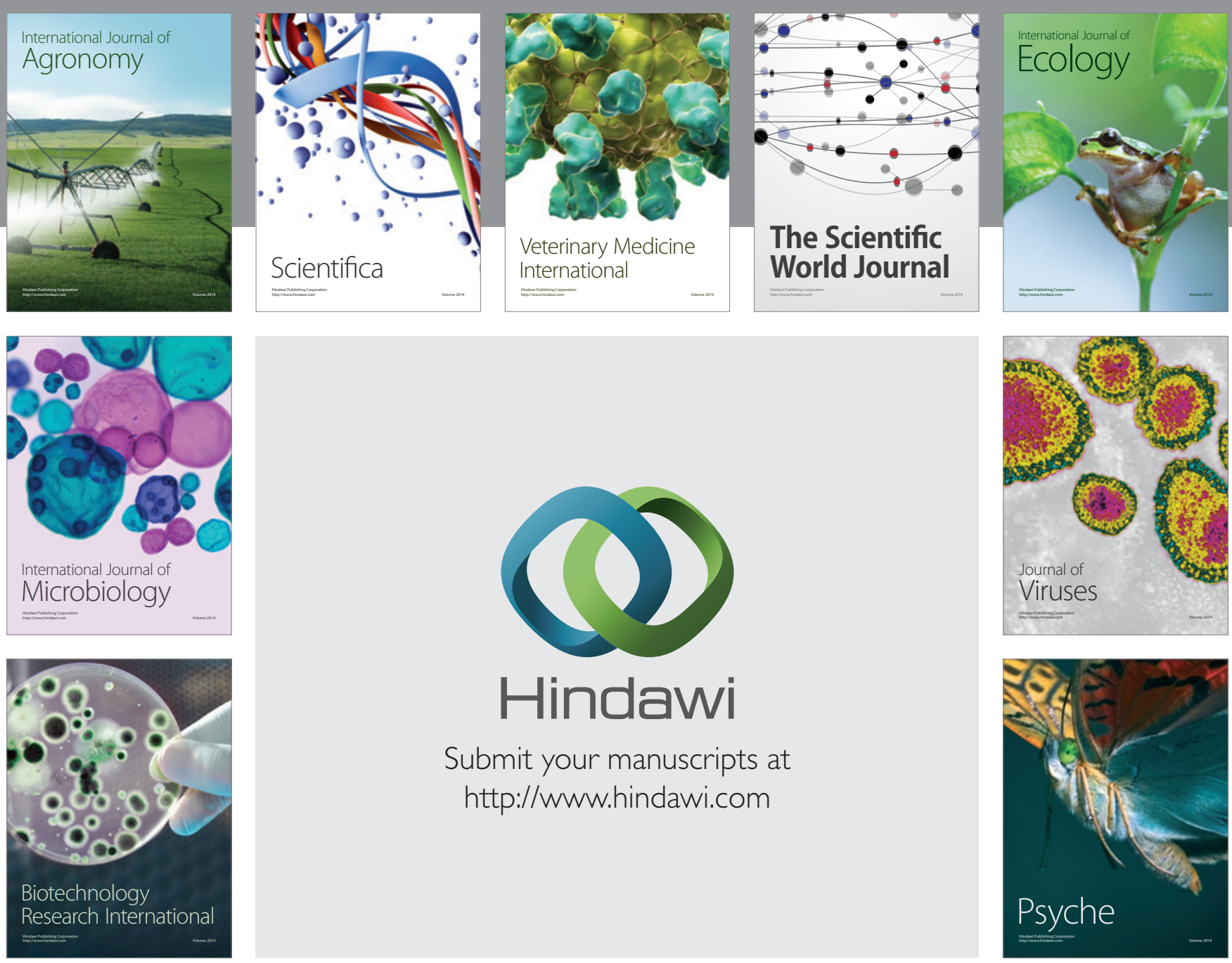

Submit your manuscripts at

http://www.hindawi.com
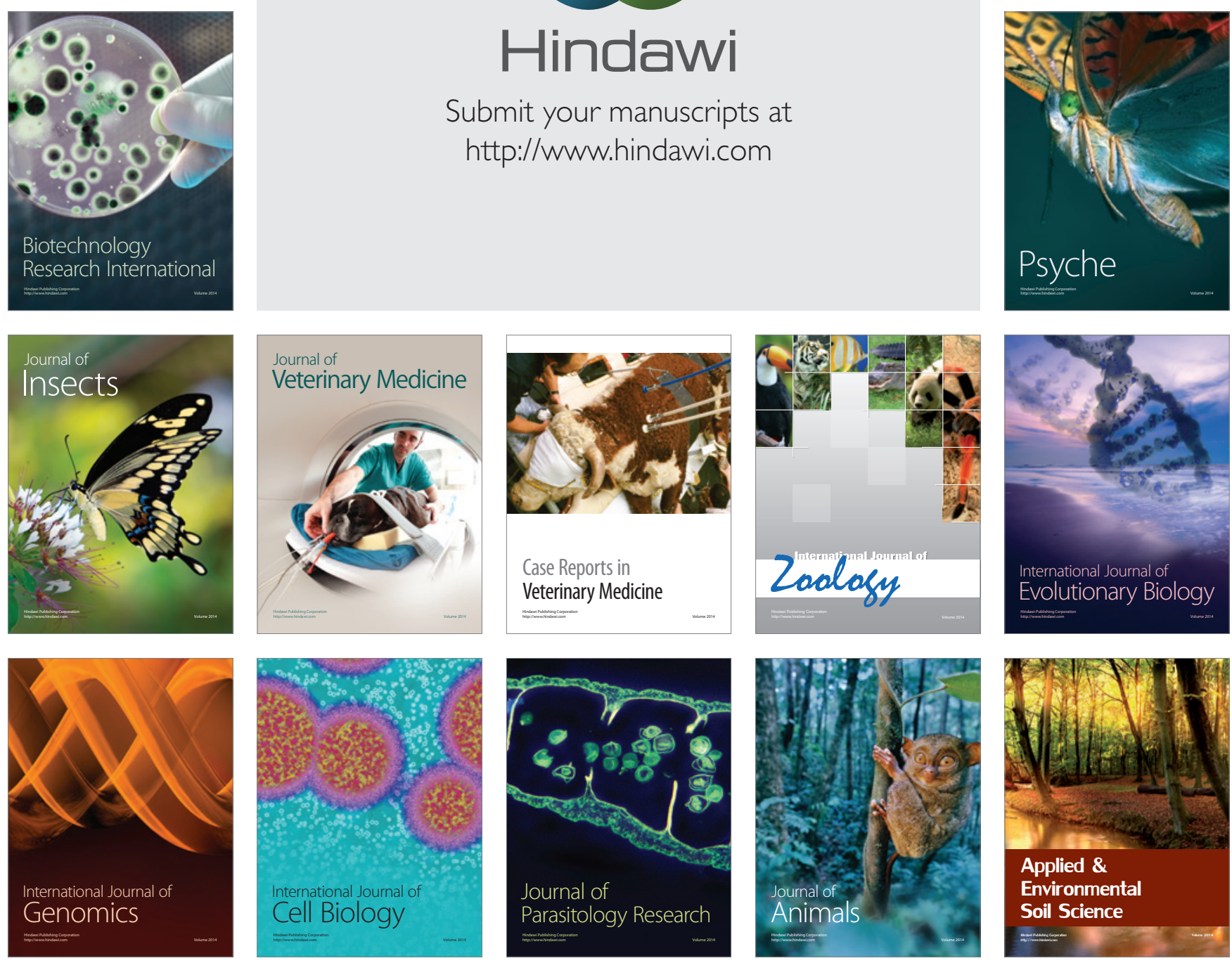